\section{Use of medicines by homeless people in Porto, Portugal}

\author{
Uso de medicamentos por pessoas sem-teto \\ no Porto, Portugal
}

\section{Uso de medicamentos por parte de personas sin techo en Oporto, Portugal}

\begin{abstract}
The objective of this study was to describe patterns of medication use among homeless adults from the city of Porto, Portugal. We recruited 146 homeless participants in four social services institutions. Data on the use of medicines in the previous week were collected using face-to-face interviews. We described the prevalence and main correlates of use of medicines from different Anatomical Therapeutic Chemical classification (ATC) groups. A total of $56.8 \%$ of the homeless reported to have used at least one medicine in the previous week. The most frequently reported were benzodiazepines (21.9\%) and antipsychotics (15.1\%); socio-demographic characteristics, lifestyle variables and use of health care were not found to be significantly associated with their use. The prevalence was $1.4 \%$ for anti-inflammatory and antirheumatic products, and $6.2 \%$ for antihypertensives, diuretics and beta-blocking agents. Medicines pertaining to the nervous system ATC group were by far the most frequently used, while those for the treatment of other common chronic and acute conditions seem to be underused.
\end{abstract}

Homeless Persons; Drug Utilization; Pharmacoepidemiology
Helena Gama 1,2

Luís Oliveira 1

Maria de Lurdes Pereira 2,3

Ana Azevedo 1,2

Nuno Lunet 1,2

\section{Resumo}

O objetivo foi descrever os padrões de uso de medicamentos entre adultos sem-teto da cidade do Porto, Portugal. Avaliamos por entrevista pessoal 146 participantes recrutados em quatro instituições de serviços sociais. Descrevemos a prevalência e principais fatores associados ao uso de medicamentos de diferentes grupos da classificação ATC (Anatomical Therapeutic Chemical). Um total de 56,8\% dos sem-teto relatou ter usado pelo menos um medicamento na semana anterior. Os mais frequentemente utilizados foram benzodiazepinas (21,9\%) e antipsicóticos (15,1\%); não se observou relação estatisticamente significativa com características sociodemográficas, estilos de vida ou utilização de cuidados de saúde e o uso desses medicamentos. A prevalência foi de 1,4\% para anti-inflamatórios e antirreumáticos, e 6,2\% para anti-hipertensivos, diuréticos e agentes bloqueadores beta. Os medicamentos mais utilizados pertencem ao grupo ATC de sistema nervoso, enquanto os destinados ao tratamento de outras condições comuns crônicas e agudas parecem ser subutilizados.

Sem-Teto; Uso de Medicamentos; Farmacoepidemiologia 


\section{Introduction}

Homelessness is a complex phenomenon, influenced by factors acting both at the individual and societal levels, including long-term unemployment, family breakdown, poverty or high housing costs, that are becoming more frequent worldwide 1 .

The homeless are at an increased risk of premature death and experience higher levels of morbidity than the general population ${ }^{2}$. Drug dependence, alcohol abuse or mental illness are expected to be major contributors to their pattern of use of medicines ${ }^{3}$. Cardiovascular diseases are also important causes of the overall burden of disease among the homeless 1 .

Previous studies on the patterns of medication use by homeless subjects addressed mainly the treatments for HIV/AIDS, tuberculosis or mental illness 2,4,5; overviews of the use of medicines by these population groups are scarce 6,7 . However, it is known that the homeless often rely in emergency departments as a primary source of care, and have difficulties in complying with treatments, especially chronic medication 2,7 .

To our knowledge no drug utilization studies targeting homeless people have been conducted in Portugal, a setting where those subjects that do not possess the financial means to support the standard fees defined by the National Health Service (NHS) or the cost of medicines (the NHS contibutes with $15 \%$ to $90 \%$, generaly depending on the characteristics of the drugs and their indications) are entitled to free healthcare assistance and may benefit from a special cost-sharing regimen for prescription medicines 8 . We described patterns of use of medication among homeless adults from the city of Porto.

\section{Methods}

Between February and September 2009 we recruited homeless adults through venue-based sampling and systematic selection, as described previously 9 . Briefly, the participants were selected among the subjects attending social services institutions that provide accommodation or assistance; three of the 11 local organizations that were contacted agreed to participate, namely one that provided accommodation to homeless people in two homeless hostels and two institutions that managed meal programs. The present analysis includes only the subjects classified as "houseless" according to the European Federation of Organizations Working with the People who are Homeless (FEANTSA) 1.
The eligible attendants of each setting in the days selected for recruitment (which covered all the days of the week) were listed by the directors of each institution and invited to take part in the study ( $\mathrm{n}=188)$. The use of medicines was assessed through the question "During the past week did you take any medication?". Those answering "yes" were asked to indicate the name (preferably the trade name) and indication for use of each medicine. The medicines reported were coded according to the Anatomic Therapeutic Chemical (ATC) classification system, up to the fifth level, depending on the information provided by the participants (name of medicines and/or indication for use; for $21.7 \%$ of the medicines reported only the latter was available), and further grouped for analysis.

This investigation was approved by the Ethics Committee of the São João Hospital, Porto, and all participants provided written informed consent.

\section{Results}

A total of 146 participants underwent face-toface interviews $(77.6 \%$ of those invited). Their median age was 45 years (interquartile range: $37-$ 53), most were male (86.3\%), Portuguese $(87.7 \%)$ and unemployed $(78.8 \%)$, and $48.0 \%$ had less than four years of education. The median duration of the participants' homelessness was 24 months (interquartile range: $3-53$ ).

The use of at least one medicine in the previous week was reported by $56.8 \%$ of the homeless (total number of medicines: 189; number of medicines/person: median, 2, range, 1-8). It was possible to assign a code of the ATC up to the $5^{\text {th }}$ (chemical substance), $4^{\text {th }}$ (chemical subgroup), $3^{\text {rd }}$ (pharmacological subgroup), 2nd (therapeutic subgroup) or 1st (anatomic main group) levels to $72.5 \%, 9.5 \%, 7.9 \%, 7.4 \%$ and $2.1 \%$ of all medicines recalled, respectively. The participants reported that $95.8 \%$ of the medicines were obtained with a medical prescription.

Nervous system drugs were the most frequently reported, especially benzodiazepines, antipsychotics and drugs used in opioid dependence. Only $1.4 \%$ of the participants reported the use of anti-inflammatory and antirheumatic products, and $1.4 \%$ referred preparations for cough and cold (ATC R05) (Table 1).

The use of antihypertensives, diuretics and beta-blocking agents was reported by $6.2 \%$ of the homeless $(64.3 \%$ of those self-reporting a previous diagnosis of hypertension). Drugs used in diabetes were reported by $2.1 \%$ of the participants (27.3\% of those self-reporting diabetes) and $6.2 \%$ 
Prevalence of use of medicines from different groups/subgroups of the Anatomical Therapeutic Chemical (ATC) classification system in the previous week by homeless people $(\mathrm{N}=146)$.

\begin{tabular}{lcc}
\hline Group & ATC code & \% \\
\hline Drugs used in diabetes & A10 & 2.1 \\
Antihypertensives, diuretics and beta-blocking agents & C02, C03, C04, C07, C08, C09 & 6.2 \\
Lipid modifying agents & C10 & 6.2 \\
Antiinfectives for systemic use & J01, J04, J05 & M01 \\
Anti-inflammatory and antirheumatic products & N & 1.4 \\
Nervous system & N05BA, N05CD & 21.9 \\
Benzodiazepines & N05AA, N05AD, N05AH, N05AL, N05AX \\
Antipsychotics & N07B & 15.1 \\
Drugs used in opioid dependence & N03 & 11.0 \\
Anti-epileptics & N02 & 5.5 \\
Analgesics & N04 \\
Anti-Parkinson drugs & N06A, N06CA \\
Antidepressants & R03, R05 \\
Respiratory system & & 3.1 \\
Other/unknown & 3.4 \\
\hline
\end{tabular}

of the homeless were using anti-dyslipidemic drugs $(28.6 \%$ of those self-reporting a previous diagnosis of dyslipidemia).

A total of 15 participants reported to be infected with HIV; one-third were treated with antivirals for systemic use (ATC J05).

The use of benzodiazepines or antipsychotics was much less frequent in men $(\mathrm{PR} \approx 0.5)$, benzodiazepines were used twice more frequently by subjects that had been imprisoned $(\mathrm{PR}=2.02)$ and the use of antipsychotics was strongly associated with smoking $(P R=5.52)$, although these associations were not statistically significant. Among the subjects that did not attend a health care facility in the previous year, $15.4 \%$ and $7.7 \%$ reported the use of benzodiazepines and antipsychotics, respectively (Table 2).

\section{Discussion}

This study shows a high overall prevalence of medicine use by homeless people in the previous week. The nervous system medicines were by far the most frequently reported, especially benzodiazepines, antipsychotics and drugs for opioid dependence, while the reported use of drugs for the treatment of many common chronic and acute conditions is likely to reflect underuse.

In Portugal, subjects having no financial means to support the relatively small fees practiced in the NHS are entitled to free health care assistance, and the reimbursement of costs with medicines may reach $100 \%{ }^{8}$. The fact that the latter applies only to prescribed drugs helps to explain the very high percentage of medicines acquired with medical prescription reported by this population. However, social desirability bias may also have accounted for these observations.

The study of "hard-to-reach" populations, such as the homeless, is challenged by difficulties in recruiting representative samples and gaining the confidence of potential participants. Although a random sample of the homeless people could not be obtained, the venue-based sampling was conducted in support institutions that are meeting places where homeless tend to concentrate, and are representative of the institutions of the same type in Porto; the other institutions that were invited are similar to those that participated in their objectives and services provided, and are therefore expected to target similar populations 9 . Furthermore, our sample is expected to include at least one-tenth of the homeless living in Porto, since the population of homeless people in the city was estimated to range between 358 and 1,394 10 .

Regarding data collection, we took into account information both on the medicines' names and the indications for use to minimize misclassification and missing data, and the small recall period aimed to keep the expected recall bias to a minimum. Although the latter may have contributed to the low reporting of medicines used 


\begin{tabular}{|c|c|c|c|c|}
\hline & \multicolumn{4}{|c|}{ Use of nervous system medicines } \\
\hline & \multirow{2}{*}{\multicolumn{2}{|c|}{$\begin{array}{l}\text { Benzodiazepines } \\
\text { (ATC: N05BA+N05CD) }\end{array}$}} & \multirow{2}{*}{\multicolumn{2}{|c|}{$\begin{array}{l}\text { Antipsychotics } \\
\text { (ATC: N05AA+N05AX+N05AD+N05AH+N05AL) }\end{array}$}} \\
\hline & & & & \\
\hline & n (\%) & Adjusted * PR $(95 \% \mathrm{Cl})$ & n (\%) & Adjusted * PR $(95 \% \mathrm{Cl})$ \\
\hline \multicolumn{5}{|l|}{ Sex } \\
\hline Female & $8(40.0)$ & 1.00 [reference] & $6(30.0)$ & 1.00 [reference] \\
\hline Male & $24(19.0)$ & $0.50(0.22-1.16)$ & $16(12.7)$ & $0.49(0.18-1.28)$ \\
\hline \multicolumn{5}{|l|}{ Age (years) } \\
\hline $18-39$ & $10(22.2)$ & 1.00 [reference] & $8(17.8)$ & 1.00 [reference] \\
\hline $40-49$ & $11(23.4)$ & $1.23(0.50-3.06)$ & $6(12.8)$ & $0.75(0.25-2.25)$ \\
\hline $50-59$ & $9(22.5)$ & $1.26(0.47-3.40)$ & $8(20.0)$ & $0.97(0.34-2.78)$ \\
\hline$\geq 60$ & $2(14.3)$ & $0.85(0.18-4.10)$ & $0(0.0)$ & - \\
\hline \multicolumn{5}{|c|}{ Education (years) } \\
\hline$\leq 4$ & $12(16.2)$ & 1.00 [reference] & $7(9.5)$ & 1.00 [reference] \\
\hline $5-9$ & $16(29.1)$ & $1.60(0.72-3.55)$ & $12(21.8)$ & $1.97(0.74-5.25)$ \\
\hline$\geq 10$ & $4(23.5)$ & $1.26(0.40-4.00)$ & $3(17.6)$ & $2.03(0.51-8.00)$ \\
\hline \multicolumn{5}{|c|}{ Duration of homelessness (months) } \\
\hline$\leq 1$ & $2(14.3)$ & $0.68(0.15-3.03)$ & $2(14.3)$ & $0.62(0.14-2.86)$ \\
\hline $2-11$ & $12(24.5)$ & $1.18(0.54-2.57)$ & $4(8.2)$ & $0.38(0.12-1.18)$ \\
\hline$\geq 12$ & $17(20.7)$ & 1.00 [reference] & $16(19.5)$ & 1.00 [reference] \\
\hline \multicolumn{5}{|c|}{ Current smoking } \\
\hline No & $5(16.7)$ & 1.00 [reference] & $1(3.3)$ & 1.00 [reference] \\
\hline Yes & $27(23.3)$ & $1.67(0.59-4.72)$ & $21(18.1)$ & $5.52(0.71-43.16)$ \\
\hline \multicolumn{5}{|c|}{ Current alcohol consumption } \\
\hline No & $10(25.0)$ & 1.00 [reference] & $9(22.5)$ & 1.00 [reference] \\
\hline Yes & $2(20.8)$ & $1.03(0.44-2.41)$ & $13(12.3)$ & $0.58(0.22-1.53)$ \\
\hline \multicolumn{5}{|c|}{ Use of illicit drugs (previous year) } \\
\hline No & $21(18.9)$ & 1.00 [reference] & $15(13.5)$ & 1.00 [reference] \\
\hline Yes & $11(31.4)$ & $1.78(0.74-4.28)$ & $7(20.0)$ & $1.39(0.48-4.01)$ \\
\hline \multicolumn{5}{|c|}{ Imprisonment (ever) } \\
\hline No & $22(19.1)$ & 1.00 [reference] & 19 (16.5) & 1.00 [reference] \\
\hline Yes & $10(32.3)$ & $2.02(0.93-4.39)$ & $3(9.7)$ & $0.66(0.19-2.25)$ \\
\hline \multicolumn{5}{|c|}{ Attended a healthcare facility (previous year) } \\
\hline No & $4(15.4)$ & 1.00 [reference] & $2(7.7)$ & 1.00 [reference] \\
\hline Yes & $28(23.2)$ & $1.32(0.45-3.86)$ & $20(16.7)$ & $2.21(0.51-9.66)$ \\
\hline \multicolumn{5}{|c|}{ Hospitalization (previous year) } \\
\hline No & $22(21.0)$ & 1.00 [reference] & $14(13.3)$ & 1.00 [reference] \\
\hline Yes & $8(29.6)$ & $1.46(0.63-3.36)$ & $6(22.2)$ & $1.73(0.65-4.62)$ \\
\hline
\end{tabular}

95\% Cl: 95\% confidence interval; ATC: Anatomical Therapeutic Chemical classification system; PR: prevalence ratio.

* Adjusted for sex, age, education and duration of homelessness.

for acute conditions, such as non-steroidal antiinflammatory drugs or cough and cold preparations, the prevalences were much lower the expected.

Unpublished data from the general population from the same city ${ }^{9}$ shows that anti-dyslipidemic drugs, antihypertensives, anti-inflamma- tory drugs and other medications (e.g. vitamins, proto-pump inhibitors) are used more often by the general population, whereas among the homeless the prevalence of the use of antiinfectives for systemic use and nervous system drugs (except anti-depressants) is much higher. 
The interpretation of the high prevalence of nervous system drugs is limited by the lack of information on medical conditions requiring the use of these medicines. Psychiatric disorders are known risk factors for homelessness, which is also associated with addiction to alcohol or illicit drugs 11,12. These conditions may be either the cause or the consequence of each other, and therefore the cross-sectional nature of our study precludes the identification of the temporal relation. Nevertheless, the relative contribution of these medicines to the overall consumption, and the lack of association between the use of benzodiazepines and antipsychotics and the utilization of health care services suggest that efforts should be developed to promote a more rational use of medicines in this population.

The lack of adherence to treatments as well as the underuse of drugs for asymptomatic chronic conditions, such as hypertension or dyslipidemia, also identified in other studies, need to be taken into consideration from a public health perspective $2,7,13$.

In conclusion, the determinants and implications of this pattern of use of medicines with regard to public health need to be further assessed, along with the promotion of a rational use of medicines in this underprivileged population.

\section{Resumen}

El objetivo fue describir los padrones de uso de medicamentos entre adultos sin techo de la ciudad de Oporto, Portugal. Evaluamos por entrevista personal a 146 participantes reclutados en cuatro instituciones de servicios sociales. Describimos la prevalencia y principales factores asociados al uso de medicamentos de diferentes grupos de la clasificación ATC (Anatomical Therapeutic Chemical). Un total de 56,8\% de los sin techo informó haber usado por lo menos un medicamento durante la semana anterior. Los más frecuentemente utilizados fueron benzodiazepinas $(21,9 \%)$ y antipsicóticos (15,1\%); no se observó relación estadísticamente significativa con características sociodemográficas, estilos de vida o utilización de cuidados de salud y el uso de estos medicamentos. La prevalencia fue de 1,4\% para los anti-inflamatorios y antirreumáticos, y un 6,2\% para antihipertensivos, diuréticos y agentes bloqueadores beta. Los medicamentos más utilizados pertenecen al grupo ATC del sistema nervioso, mientras que los destinados al tratamiento de otras condiciones crónicas comunes y agudas parecen que están subutilizados.

Persona Sin Hogar; Utilización de Medicamentos; Farmacoepidemiología

\section{Contributors}

H. Gama collaborated in the study design, data analysis and interpretation, wrote the fisrst version of the manuscript and approved the final version for publication. L. Oliveira and M. L. Pereira contributed towards data collection, study design, critical revision of relevant intellectual content and approval of the final version for publication. A. Azevedo contributed towards the study design, critical version of relevant intellectual content and approval of the final version for publication. $\mathrm{N}$. Lunet participated in the study design, data analysis and interpretation, critical revision of intellectual content and approval of final version for publication. 


\section{References}

1. Edgar B. European review of statistics on homelessness in Europe, 2009. Brussels: European Federation of National Organisations Working with the Homeless; 2009.

2. Dixon L, Weiden P, Torres M, Lehman A. Assertive community treatment and medication compliance in the homeless mentally ill. Am J Psychiatry 1997; 154:1302-4.

3. Haugland G, Siegel C, Hopper K, Alexander MJ. Mental illness among homeless individuals in a suburban county. Psychiatr Serv 1997; 48:504-9.

4. Sleath BL, Jackson E, Thomas KC, Galloway J, Dumain L, Thorpe J, et al. Literacy and perceived barriers to medication taking among homeless mothers and their children. Am J Health Syst Pharm 2006; 63:346-51.

5. Cunningham CO, Li X, Ramsey K, Sohler NL. A comparison of HIV health services utilization measures in a marginalized population: self-report versus medical records. Med Care 2007; 45:264-8.

6. Schumacher JE, Mennemeyer ST, Milby JB, Wallace D, Nolan K. Costs and effectiveness of substance abuse treatments for homeless persons. J Ment Health Policy Econ 2002; 5:33-42.

7. Kidder DP, Wolitski RJ, Campsmith ML, Nakamura GV. Health status, health care use, medication use, and medication adherence among homeless and housed people living with HIV/AIDS. Am J Public Health 2007; 97:2238-45.
8. Ministério da Saúde. Decreto de Lei no 48-A/2010. Regime geral das comparticipações do estado no preço dos medicamentos. Diário da República 2010; 13 mai.

9. Oliveira LP, Pereira ML, Azevedo A, Lunet N. Risk factors for cardiovascular disease among the homeless and in the general population of the city of Porto, Portugal. Cad Saúde Pública 2012; 28:1517-29.

10. Instituto de Segurança Social. Estudo dos sem-abrigo. Lisboa: Instituto de Segurança Social; 2005.

11. Breakey WR, Fischer PJ, Kramer M, Nestadt G, Romanoski AJ, Ross A, et al. Health and mental health problems of homeless men and women in Baltimore. JAMA 1989; 262:1352-7.

12. Garibaldi B, Conde-Martel A, O'Toole TP. Self-reported comorbidities, perceived needs, and sources for usual care for older and younger homeless adults. J Gen Intern Med 2005; 20:726-30.

13. Khadduri J. The 2009 annual homeless assessment report. Washington DC: U.S. Department of Housing and Urban Development; 2010.

Submitted on 16/Jan/2013

Final version resubmitted on 26/Jun/2013

Approved on 09/Sep/2013 